\title{
Increasing the efficient manufacturing process using the Tecnomatix Plant Simulation software module and another management method
}

\author{
Marek Kliment ${ }^{1}$, Peter Trebuňa ${ }^{1}$, Richard Duda ${ }^{1}$, Štefan Král ${ }^{2}$ \\ 1 Technical University of Košice, Faculty of Mechanical Engineering, Institute of \\ Management, Industrial and Digital Engineering \\ Park Komenskeho 9, Košice, Slovakia \\ marek.kliment@tuke.sk \\ peter.trebuna@tuke.sk \\ richard.duda@tuke.sk \\ ${ }_{2}$ Slovak Legal Metrology n.o., \\ Hviezdoslavova 1124/31, 97401 Banská Bystrica, Slovakia \\ kral@slm.sk
}

\begin{abstract}
Annotation: In everyday life we do not realize what a difficult process and how all the components needed to perform perfectly normal activity at the car door opening. Every business, whether engaged in the production of products or the provision of services, aims to make everything work as efficiently as possible and to achieve the maximum with the least amount of money. The paper deals with production and assembly line in selected production process. It is a manufacturing process for manufacturing car handles and their components. The manufacturing process consists of several assembly stations, which in turn ensure the product of the finished product. We analysed the process and transformed it into simulation models in Tecnomatix Plant Simulation. In addition to the software module, we used the Hoshin method, which is commonly used in industrial enterprises, to increase efficiency. This method is used in businesses that seek to develop an annual strategy to be applied at all levels of the enterprise.
\end{abstract}

\section{Introduction}

Every productive business that wants to move forward has to deal with the constant re-evaluation and resolution of all the problems that may arise in production. In order to achieve the highest production productivity, it is necessary to use all available means, both software and management, so that production, processes and human resources can be constantly improved. Such means are also software and simulation modules from the Siemens Tecnomatix portfolio [7]. One of them is Plant Simulation, which can simulate production process layouts, streamline material and logistics flows, and more. Other means to be used in this process are management methods such as: Hoshin, MTM, time frame of workflows and the like. 


\section{Production process characteristics}

The manufacturing process we've been dealing with is the car door handle holder. It's part of the component, which is located between the outer and inner door handles car (Figure 1). Using the handle holder, the handles are mounted and held together. Handler holders are a very important component in cars because we can use them to move handles. The production line is capable of producing 1,650 pieces for change. The time for making one handle holder is 110 seconds. Every 13 seconds, one finished product must come out of the line. On each post is operator. There are 10 operators on this production line and their number may change as needed. Each component has its specification, e.g. dimensions, appearance, material and the like.

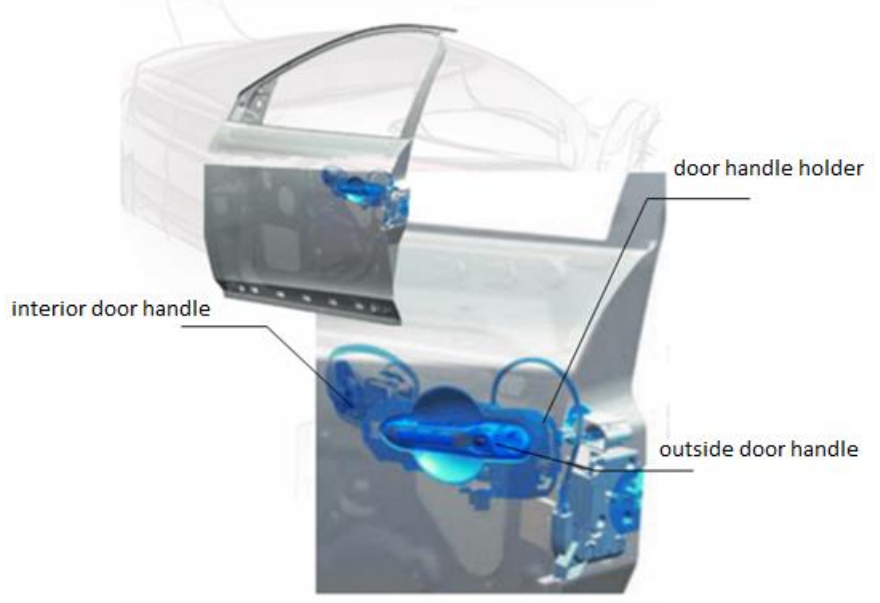

Figure 1 - A representation of a car door handle holder

This assembly process consists of assembly and testing operations [10]. Assembly operations consist of eight locations where components are connected. The result is a finished product. For assembly operations on individual posts, it is necessary to distinguish:

- left driver and passenger,

- right driver and passenger.

The components of the entire handle holder mechanism are shown in Figure 2. 


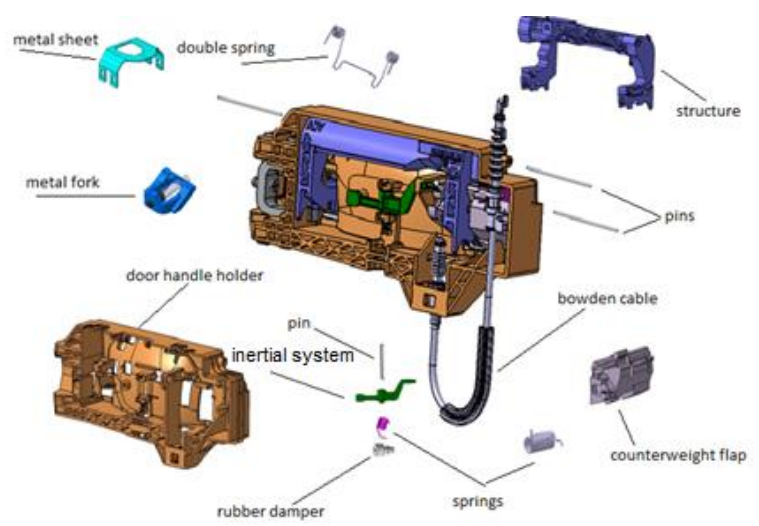

Figure 2 - Handle holder decomposition

The entire assembly process consists of the following operations:

- Inserting the rubber damper into the counterweight flap,

- Inserting the slider and springs into the counterweight flap,

- Lubrication of the saddle and the insertion of the bowden cable liner,

- Inserting double spring and fixing pins,

- Insertion and lubrication of kinematic slider and pin insertion,

- Inserting and push pins,

- Mounting inerial system,

- Pushing pins into the inerial system,

- Product testing.

The entire production process was reflected in the simulation using the Tecnomatix Plant Simulation software module. Simulation (Figure 3) also shows the schematic ground plan of the entire production process and the method of disposition of workplaces [8].

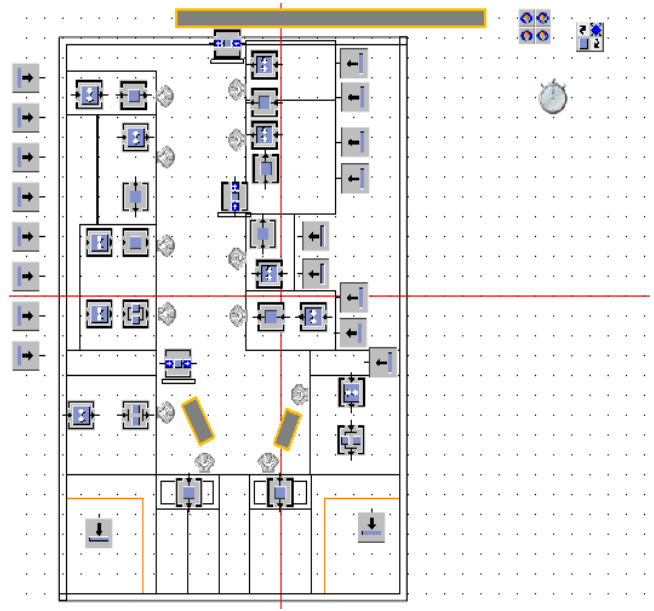

Figure 3 - Simulation of manufacturing process of car door handle holder 
On the production layout, we can see 12 jobs at each job position. In the chapters above, it has been mentioned that 10 workers serve the line. In the simulation it is possible to see the pathway, after which operators come to the line but also two shorter paths directly at the line. After this, two operators move between jobs to lines and hold 2 posts in the production process [4].

\section{Proposals to increase the efficiency of the production process}

Based on the analysis and research of the production process, we try to find the most effective options that can help to increase efficiency in the future.

Among the suggestions for improvement include:

- machine modification,

- shortening production time.

\subsection{Machine modification}

In the analysis of the production process, in addition to evaluating the time aspect of the production process, we also dealt with the operation of the equipment at the individual assembly sites [13]. We have reviewed the possibilities of modifying individual devices and their capabilities. In this analysis, it was found that it is possible to modify some devices and thereby shorten the time of some operations. The modification succeeded in unifying the first two assembly stations, reducing the production process by 13.6 seconds (Figure 4). This proposal will succeed in eliminating the need for one operator, which in the manufacturing process ensures the insertion of the rubber damper. In addition, when inserting a rubber damper with the aid of a machine, the incorrect insertion of this component into the structure is eliminated.

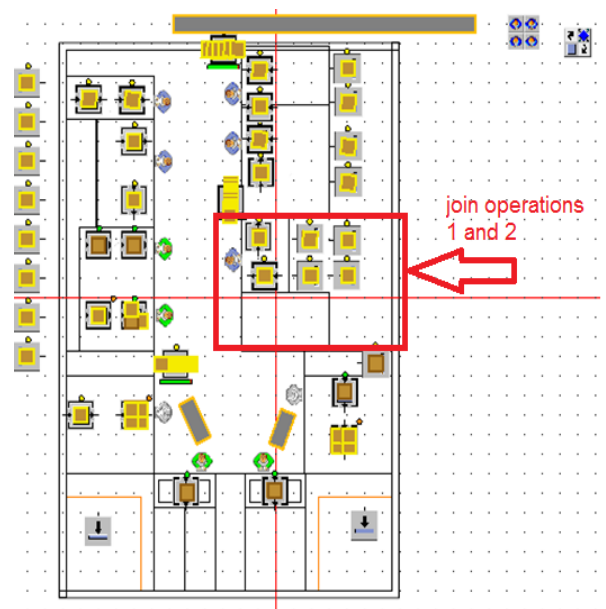

Figure 4 - Proposal of machine modification in simulation 


\subsection{Shortening production operations using the Hoshin method}

The second option to increase the efficiency of the production process is to shorten production operations. In this variant we used the Hoshin method and the MTM method [12]. We made an analysis on the production line, which consisted of measuring the times. On the production line we made 20 measurements during one change. We measured from component grip to product completion [9].

Table 1 - Production operations times

\begin{tabular}{|c|c|c|c|c|c|c|c|c|c|}
\hline $\begin{array}{l}\text { Nr. } \\
\text { meas. }\end{array}$ & $\begin{array}{l}\text { Pos. } \\
\text { nr. } 1\end{array}$ & $\begin{array}{l}\text { Pos. } \\
\text { nr. } 2\end{array}$ & $\begin{array}{l}\text { Pos. } \\
\text { nr. } 3\end{array}$ & $\begin{array}{l}\text { Pos. } \\
\text { nr. } 4\end{array}$ & $\begin{array}{l}\text { Pos. } \\
\text { nr. } 5\end{array}$ & $\begin{array}{l}\text { Pos. } \\
\text { nr. } 6\end{array}$ & $\begin{array}{l}\text { Pos. } \\
\text { nr. } 7\end{array}$ & $\begin{array}{l}\text { Pos. } \\
\text { nr. } 8\end{array}$ & $\begin{array}{l}\text { Pos. } \\
\text { nr. } 9\end{array}$ \\
\hline 1. & 7,4 & 14,0 & 13,8 & 12,5 & 16,2 & 13,0 & 12,1 & 22,5 & 26,9 \\
\hline 2. & 7,8 & 14,1 & 12,3 & 12,3 & 16,1 & 13,3 & 13,5 & 23,6 & 24,7 \\
\hline 3. & 8,6 & 13,3 & 11,6 & 12,5 & 16,3 & 14,3 & 13,5 & 23,7 & 24,3 \\
\hline 4. & 8,7 & 13,1 & 12,4 & 13,5 & 16,8 & 13,7 & 13,2 & 22,6 & 24,7 \\
\hline 5. & 8,8 & 13,1 & 12,1 & 11,8 & 16,2 & 13,9 & 12,5 & 24,4 & 25,1 \\
\hline 6. & 8,1 & 13,1 & 12,9 & 12,2 & 15,3 & 14,9 & 12,6 & 23,5 & 23,1 \\
\hline 7. & 8,7 & 13,2 & 14,1 & 12,0 & 15,7 & 12,8 & 12,1 & 22,1 & 24,4 \\
\hline 8. & 8,9 & 12,7 & 13,2 & 11,3 & 16,3 & 13,3 & 12,1 & 22,1 & 24,8 \\
\hline 9. & 8,8 & 13,7 & 14,1 & 10,8 & 15,7 & 13,5 & 11,4 & 22,4 & 24,7 \\
\hline 10. & 8,8 & 14,1 & 13,1 & 11,9 & 16,4 & 13,7 & 11,8 & 23,0 & 24,3 \\
\hline 11. & 8,1 & 13,5 & 12,1 & 11,3 & 15,2 & 13,6 & 13,1 & 22,1 & 24,9 \\
\hline 12. & 8,5 & 13,3 & 13,1 & 12,1 & 17,4 & 13,8 & 11,6 & 22,7 & 24,4 \\
\hline 15. & 7,8 & 13,1 & 13,3 & 12,1 & 16,3 & 13,9 & 12,4 & 22,5 & 26,8 \\
\hline 14. & 8,1 & 13,3 & 13,2 & 12,7 & 15,9 & 12,6 & 12,1 & 22,6 & 25,4 \\
\hline 15. & 8,9 & 13,1 & 12,5 & 12,5 & 16,9 & 12,6 & 11,4 & 22,1 & 25,1 \\
\hline 16. & 8,1 & 13,7 & 12,1 & 13,2 & 17,4 & 12,3 & 11,7 & 23,0 & 25,8 \\
\hline $1 \%$ & 8,0 & 13,6 & 12,5 & 12,6 & 17,7 & 12,9 & 11,4 & 22,7 & 24,6 \\
\hline & 7,8 & 12,9 & 12,5 & 11,5 & 15,9 & 13,1 & 11,2 & 22,5 & 24,4 \\
\hline 19. & 8,8 & 13,8 & 12,6 & 11,2 & 17,3 & 13,5 & 12,5 & 23,1 & 25,3 \\
\hline 20. & 8,1 & 12,8 & 13,7 & 11,1 & 17,1 & 15,4 & 11,9 & 22,5 & 24,6 \\
\hline Overall & 166,8 & 267,4 & 257,1 & 241,1 & 328,0 & 269,9 & 244,0 & 455,5 & 498,0 \\
\hline Average & 8,3 & 13,4 & 12,9 & 12,1 & 16,4 & 13,5 & 12,2 & 22,8 & 24,9 \\
\hline Minimum & 7,4 & 12,7 & 11,6 & 10,8 & 15,2 & 12,3 & 11,2 & 22,1 & 23,1 \\
\hline In $\%$ & $13 \%$ & $5 \%$ & $11 \%$ & $11 \%$ & $8 \%$ & $10 \%$ & $9 \%$ & $3 \%$ & $8 \%$ \\
\hline
\end{tabular}

In the Table 1 shows measurements on a production line. Position 9 includes one test station and scan labels on the product. The times of individual operations are not the same, but there are small deviations.

In the graph (Figure 5) we can see how the individual operations on the posts move unevenly. Our goal is to break down individual operations into smaller operations. We choose the optimum time for operations to be at about the same time. Small deviations are permitted. 


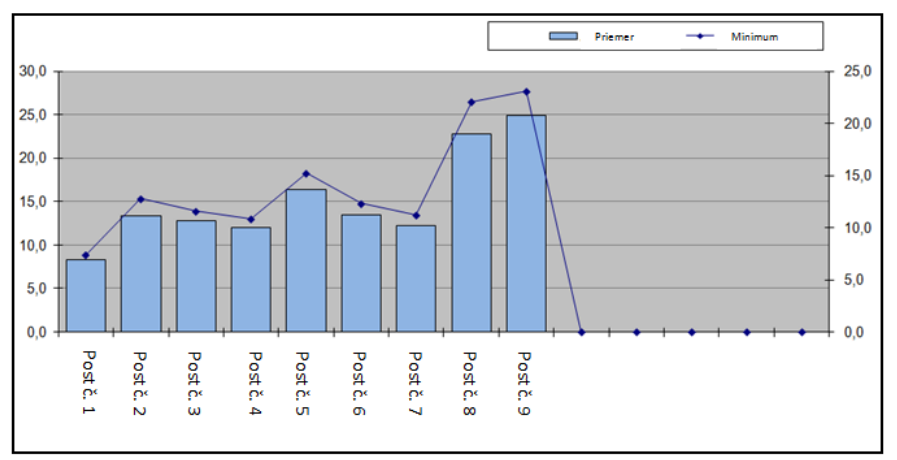

Figure 5 - Production operations times

We use the Hoshin method for this improvement design. We did a lot of measurements. Our goal was to combine some operations [8]. By we increase efficiency, we go in depth. We split the operations into smaller operations using the MTM method (Table 2) [3].

The operations performed on the production line were divided into small and more detailed operations. In this improvement proposal we also envisaged variant no. 1 thus with the modification of the machine [14].

\section{Table 2 - Separation of operations}

\begin{tabular}{|c|c|c|}
\hline Position & Operation type & $\begin{array}{l}\text { Time in } \\
\text { sec. }\end{array}$ \\
\hline \multirow{4}{*}{ Pos. Nr. 1} & Lubricating the counterweight flap & \multirow{4}{*}{$12,3 \mathrm{~s}$} \\
\hline & Slider insertion & \\
\hline & Inserting the spring & \\
\hline & Inserting rubber damper & \\
\hline \multirow{3}{*}{ Pos. Nr. 2} & Lubrication of the handle holder & $4,1 \mathrm{~s}$ \\
\hline & Cable fixation & $3,2 \mathrm{~s}$ \\
\hline & Inserting the lever & $5,6 \mathrm{~s}$ \\
\hline \multirow{3}{*}{ Pos. Nr. 3} & Spring lubrication & $4,1 \mathrm{~s}$ \\
\hline & Inserting the spring & $4,8 \mathrm{~s}$ \\
\hline & Inserting the pin into the lever & $3,2 \mathrm{~s}$ \\
\hline \multirow[t]{2}{*}{ Pos. Nr. 4} & $\begin{array}{l}\text { Insert slider into internal structure } \\
\text { and erase }\end{array}$ & $7 \mathrm{~s}$ \\
\hline & Insert internal structure and pin & $9,4 \mathrm{~s}$ \\
\hline \multirow{2}{*}{ Pos.Nr. 5} & Inserting a pin & $3,6 \mathrm{~s}$ \\
\hline & Pressing pins & $9,9 \mathrm{~s}$ \\
\hline \multirow{3}{*}{ Pos. Nr. 6} & Lubrication of inertial system & $3,7 \mathrm{~s}$ \\
\hline & $\begin{array}{l}\text { Inserting a spring into an inertial } \\
\text { system }\end{array}$ & $3,9 \mathrm{~s}$ \\
\hline & $\begin{array}{l}\text { Inserting an inertial system into the } \\
\text { handle holder }\end{array}$ & $4,6 \mathrm{~s}$ \\
\hline \multirow{2}{*}{ Pos.Nr. 7} & Pushing pins into an inertial system & $18,7 \mathrm{~s}$ \\
\hline & Inserting sheet metal & $4,1 \mathrm{~s}$ \\
\hline \multirow[t]{2}{*}{ Pos. Nr. 8} & $\begin{array}{l}\text { Insert the metal fork into the handle } \\
\text { holder }\end{array}$ & $4,0 \mathrm{~s}$ \\
\hline & Testing the handle holder & $13,6 \mathrm{~s}$ \\
\hline Pos. Nr. 9 & Car Door Handle Holder Pack & $7,3 \mathrm{~s}$ \\
\hline
\end{tabular}

In this improvement proposal, we have tried to align the operations so that there are no time jumps on each production post. Our goal was to improve production times and reduce the number of operators on the production line. 
Table 3 - Alignment of manufacturing operations

\begin{tabular}{|c|c|c|c|}
\hline Position & Operation type & \multicolumn{2}{|c|}{ Time in sec. } \\
\hline \multirow{5}{*}{ Pos.Nr. 1} & $\begin{array}{l}\text { Lubricating the } \\
\text { counterweight flap }\end{array}$ & \multirow{4}{*}{$12,3 \mathrm{~s}$} & \multirow{5}{*}{$16,4 \mathrm{~s}$} \\
\hline & Slider insertion & & \\
\hline & Inserting the spring & & \\
\hline & Inserting rubber damper & & \\
\hline & $\begin{array}{l}\text { Lubrication of the handle } \\
\text { holder }\end{array}$ & $4,1 \mathrm{~s}$ & \\
\hline \multirow{4}{*}{ Pos.Nr 2} & Cable fixation & $3,2 \mathrm{~s}$ & \multirow{4}{*}{$17,7 \mathrm{~s}$} \\
\hline & Inserting the lever & $5,6 \mathrm{~s}$ & \\
\hline & Spring lubrication & $4,1 \mathrm{~s}$ & \\
\hline & Inserting the spring & $4,8 \mathrm{~s}$ & \\
\hline \multirow{3}{*}{ Pos.Nr. 3} & $\begin{array}{l}\text { Inserting the pin into the } \\
\text { lever }\end{array}$ & $3,2 \mathrm{~s}$ & \multirow[t]{3}{*}{19,6} \\
\hline & $\begin{array}{l}\text { Insert slider into internal } \\
\text { structure and erase }\end{array}$ & $7 \mathrm{~s}$ & \\
\hline & $\begin{array}{l}\text { Insert internal structure } \\
\text { and pin }\end{array}$ & $9,4 \mathrm{~s}$ & \\
\hline \multirow{3}{*}{ Pos.Nr. 4} & Inserting a pin & $3,6 \mathrm{~s}$ & \multirow[t]{3}{*}{17,2} \\
\hline & Pressing pins & $9,9 \mathrm{~s}$ & \\
\hline & $\begin{array}{l}\text { Lubrication of inertial } \\
\text { system }\end{array}$ & $3,7 \mathrm{~s}$ & \\
\hline \multirow{4}{*}{ Pos.Nr. 5} & $\begin{array}{l}\text { Inserting a spring into an } \\
\text { inertial system }\end{array}$ & $3,9 \mathrm{~s}$ & \multirow[t]{4}{*}{16,6} \\
\hline & $\begin{array}{l}\text { Inserting an inertial system } \\
\text { into the handle holder }\end{array}$ & $4,6 \mathrm{~s}$ & \\
\hline & Inserting sheet metal & $4,1 \mathrm{~s}$ & \\
\hline & $\begin{array}{l}\text { Insert the metal fork into } \\
\text { the handle holder }\end{array}$ & $4,0 \mathrm{~s}$ & \\
\hline Pos. Nr. 6 & $\begin{array}{l}\text { Pushing pins into an } \\
\text { inertial system }\end{array}$ & $18,7 \mathrm{~s}$ & 18,7 \\
\hline \multirow[b]{2}{*}{ Pos. Nr. 7} & Testing the handle holder & $13,6 \mathrm{~s}$ & \multirow[t]{2}{*}{20,9} \\
\hline & $\begin{array}{l}\text { Car Door Handle Holder } \\
\text { Pack }\end{array}$ & $7,3 \mathrm{~s}$ & \\
\hline
\end{tabular}

In the Table 3, we have aligned production operations using the Hoshin and MTM methods. Of the nine stations, we arrived at seven stations [2].

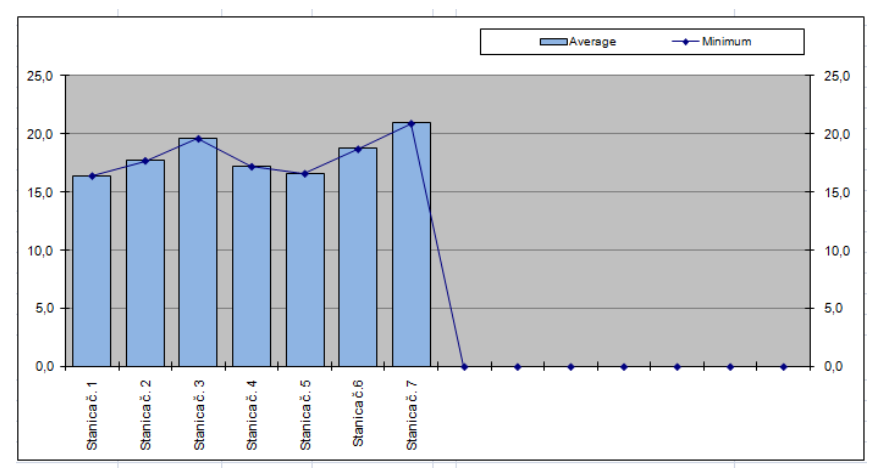

Figure 6 - Graph of manufacturing operations after alignment

In the graph (Figure 6), we can see the movement of times on individual posts after the times in production operations were aligned. It is obvious that the movement of times is much more uniform than in the first case [5].

The proposal in alignment operations we have spilled over into the simulation. As we can see on the line, there is another operator missing from this 
proposal and it is visible from the graph above that the flow of the production process has also improved [11].

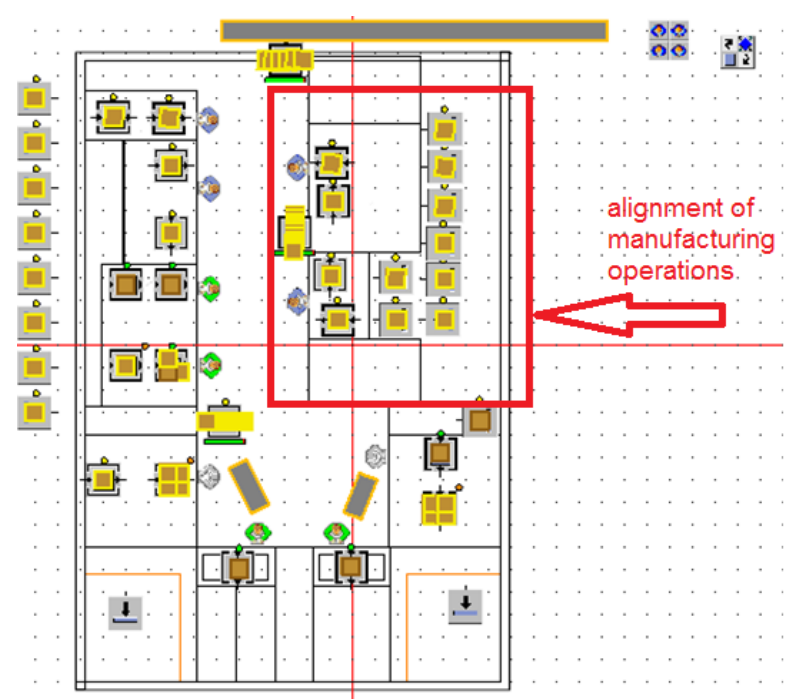

Figure 7 - Simulation design of the reconciliation operation

\section{CONCLUSION}

As is evident from the proposals and analyses, any company that seeks to constantly improve must necessarily use all the means available to achieve this goal. To improve the efficiency of production processes and to save both financial and human resources, optimization options are reviewed at every stage of the product life cycle. This requires both software support and management methods. Changes must be promoted at all levels of the business, from the highest to the lowest, to make the improvement comprehensive and effective. By applying the submitted proposals, the company can save both financial and human resources and reduce the time of production of the product in question. Harmonize operations will improve the continuity of the production process .

\section{Acknowledgment}

This article was created by implementation of the grant projects VEGA 1/0708/16 Development of a new research methods for simulation, assessment, evaluation and quantification of advanced methods of production and APVV-17-0258 Digital engineering elements application in innovation and optimization of production flows and KEGA 030TUKE-4/2017 Implementation of innovative instruments for increasing the quality of higher education in the 5.2 .52 Industrial engineering field of study

\section{References}

[1] Bangsow, S. Tecnomatix Plant Simulation: Modeling and Programming by Means of Examples. Switzerland: Springer-Verlag Berlin Heidelberg, 2016. 
[2] Dulina, L., Rakyta, M., Sulirova, I., Šeligova, M. Improvement of the Production System. In: Smart City $360^{\circ} .2^{\text {nd }}$ EAI international Summit: revised selected papers. Ghent: EAI, 2017.

[3] Edl, M., Lerher, T., Rosi, B. Energy efficiency model for the mini-load automated storage and retrieval systems. International Journal of Advanced Manufacturing Technology, 2013, s. 1-19. ISSN: 0268-3768, (2013).

[4] Gregor, M., Hodon, R., Biňasová, V., Dulina, L., Gašo, M. Design of Simulation-Emulation Logistics System. In: MM Science Journal, 2018, p. 2498-2502.

[5] Kłos S. Implementation of the AHP method in ERP-based decision support systems for a new product development. Communications in Computer and Information Science, 2015. ISSN 1865-0929.

[6] Laciak, M., Sofranko, M. Designing of the technological line in the SCADA system PROMOTIC. In: Proceedings of the $201314^{\text {th }}$ International Carpathian Control Conference, Rytro, Poland, 2013.

[7] Ottova, M., Kudrna, J., Poor, P., Edl, M. New Possibilities of Knowledge Transfer by Playing Manager Games. In: Procedia - Social And Behavioral Sciences, 2015, vol. 174, p. 3738-3742.

[8] Poór, P., Šimon, M., Karková, M. CMMS as an effective solution for company maintenance costs reduction. Production Management And Engineering Sciences, 2015, p. 241-246.

[9] Rosova, A., Malindzakova, M. Material flow - starting point for recovery of inputs in the production company. International Multidisciplinary Scientific GeoConference Surveying Geology and Mining Ecology Management, SGEM 3(5), 2014, Albena; Bulgaria.

[10] Saniuk, S., Saniuk, A., Lenort, R., Samolejova, A. Formation and planning of virtual production networks in metallurgical clusters. Metalurgija, 2014, Vol. 53, p. 725-727.

[11] Straka M., Khouri S., Rosova A., Caganova D., Culkova K. Utilization of computer simulation for waste separation design as a logistics system. International Journal of Simulation Modelling, 2018, Vol. 17, No. 4, p. 583596.

[12] Straka M., Malindzakova M., Rosova A., Trebuna P. The simulation model of the material flow of municipal waste recovery. Przemys/ Chemiczny, 2016, Vol. 95, No. 4, p. 773-777.

[13] Straka, M., Lenort, R., Khouri, S., Feliks, J. Design of large-scale logistics systems using computer simulation hierarchic structure. International Journal of Simulation Modelling, 2018, Vol. 17, No. 1, p. 105-118. 